\title{
O Conto da Aia e o aborto no Brasil: a ausência de liberdade da mulher sobre 0 próprio corpo
}

\author{
Ana Carolina Pessoa Holanda' (iD 0000-0002-5969-1913 \\ Rafael Marcílio Xerez' (iD 0000-0001-7472-6822 \\ 'Universidade de Fortaleza, Fortaleza, CE, Brasil.6081 1-905 - ppgd@unifor.br
}

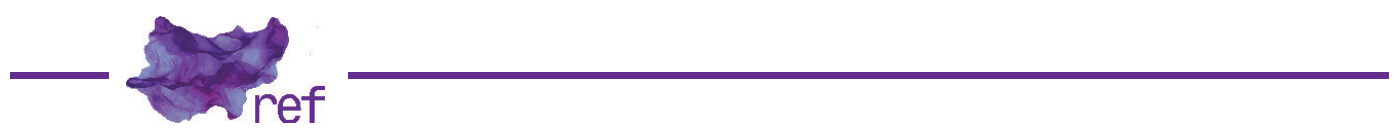

Resumo: No artigo, analisa-se a criminalização do aborto no Brasil como violação aos direitos sexuais e reprodutivos das mulheres. Tem-se, como objetivo geral, a partir da apresentação da obra literária O Conto da Aia, a análise do aborto no Brasil sob uma perspectiva penal e constitucional, com foco na decisão proferida pelo Supremo Tribunal Federal, em sede do Habeas Corpus $n^{\circ}$ 124.306, julgado em 2016. No tocante à metodologia, a pesquisa é de natureza qualitativa, descritiva e explicativa em relação aos objetivos, utilizando-se o método dedutivo, construída com fontes bibliográficas e documentais. Conclui-se que o aborto deve ser entendido como uma questão de saúde pública, cuja proibição viola direitos e liberdades das mulheres, e que a legis/ação deve ser alterada com base nas pesquisas científicas atinentes ao tema e na decisão judicial proferida.

Palavras-chave: aborto; criminalização; Brasil; direitos das mulheres.

The Handsmaid's Tale and Abortion in Brazil: the Absence of Freedom of Woman over Her Own Body

Abstract: The research analyzes the criminalization of abortion in Brazil as a violation of sexual and reproductive rights of women. The general objective is, from the presentation of the book The Handmaid's Tale, the analysis of the abortion in Brazil under a criminal and constitutional perspective, focusing on the decision of the Supreme Court, in the Habeas Corpus $n^{\circ}$ 124.306, tried in 2016. As regards to the methodology, the research is qualitative, descriptive and explanatory nature in relation to objectives, using the deductive method, built with bibliographic and documentary sources. It is concluded that abortion must be understood as a public health issue, whose ban violates women's rights and freedoms, and that the legislation should be amended on the basis of scientific research related to the theme and the judgment rendered.

Keywords: Abortion; Criminalization; Brazil; Women's rights.

\section{Introdução}

O Brasil é um Estado Democrático de Direito no qual os direitos à igualdade e à liberdade são enaltecidos na Constituição de 1988. No entanto, no tocante às mulheres, estas ainda lutam para se inserirem plenamente na sociedade, sofrendo com violência cotidiana em espaços públicos e privados e com discriminações econômicas e sociais. Um dos entraves para o exercício dos direitos fundamentais dessa parcela da população é a impossibilidade de decidir sobre a reprodução, tendo em vista que os métodos contraceptivos não são totalmente eficazes e a interrupção voluntária da gravidez, o aborto, ser proibida por lei, constituindo esta a problemática central deste artigo.

O interesse por esta temática surgiu a partir da leitura do livro The Handmaid's Tale, da escritora canadense Margaret Atwood, quando se verificou o quão pernicioso pode ser para as mulheres serem vistas notadamente como indivíduos destinados a fins reprodutivos, sem liberdades 
e direitos garantidos para decidirem se desejam ou não a maternidade. Traz-se, portanto, um breve resumo da referida narrativa, que relata a existência de uma sociedade na qual as mulheres perdem todos os seus direitos, e aquelas que ainda são férteis são destinadas à reprodução. A história contém diversos elementos reais que já aconteceram ou ainda acontecem em algum lugar e período da história humana, demonstrando a fragilidade dos direitos das mulheres e como estas ainda precisam lutar para alcançar a liberdade a fim de decidirem sobre seus próprios corpos e destinos. É utilizada como plano de fundo para a discussão do tópico central do artigo, que é a análise da criminalização do aborto no Brasil, que impossibilita as mulheres de vivenciarem plena e livremente seus direitos sexuais e reprodutivos, bem como decidir sobre o que acontece com seus organismos.

Em seguida, trata-se dos direitos sexuais e reprodutivos que foram consagrados em importantes documentos internacionais dos quais o Brasil é signatário, entendendo-se que um dos instrumentos que possibilita o exercício desses direitos é o aborto. Define-se este como a interrupção voluntária da gestação e trabalha-se no artigo com a categoria provocada, isto é, que não ocorre por condições naturais, mas em virtude da intervenção humana. Posteriormente, analisa-se o ordenamento jurídico brasileiro atinente ao tema, que considera o aborto como figura típica nos artigos 124 a 126 do Código Penal. Contudo, a conduta não é punível quando praticada por médico para salvar a vida da gestante e nos casos em que a gravidez resulta de estupro, exceções previstas no artigo 128 da referida legislação. A estas, o Supremo Tribunal Federal, em 2012, acrescentou uma exceção jurisprudencial, para permitir a interrupção da gravidez de feto anencefálico. Além disso, apresenta-se as pesquisas mais recentes desenvolvidas no Brasil e pela Organização Mundial de Saúde. Por fim, analisa-se a decisão proferida em 2016 pelo Supremo Tribunal Federal, que, com uma interpretação conforme a Constituição das normas do Código Penal, decidiu que o aborto realizado até o terceiro mês do processo gestacional não deve ser considerado crime.

Considerando que já existem pesquisas teóricas acerca da presente temática, contribui-se com esta, proporcionando-lhe um vislumbre diferenciado, mediante a análise da referida obra literária, traçando paralelos entre a ficção e a realidade, entre a vida e a arte, para provocar o questionamento acerca da problemática relativa ao aborto com uma demonstração mais explícita sobre o que representa para as mulheres não poder decidir livremente sobre seus próprios corpos em sociedades patriarcais, em que as normas jurídicas são um reflexo dessa conjuntura de desigualdade. Desse modo, compara-se a narrativa ficcional, na qual as mulheres foram destituídas de seus direitos e estão sob domínio e à disposição da sociedade, notadamente para fins reprodutivos, com a conjuntura brasileira da atualidade, de modo específico no que tange à criminalização do aborto, visto que, com esta, restringe-se a autonomia das mulheres sobre seus corpos e existências. Impossibilitando-se juridicamente a liberdade, a reprodução torna-se uma imposição, tanto na ficção como na realidade.

Reputa-se que as temáticas abordadas no artigo são relevantes, uma vez que propiciam a discussão a respeito do problema referente à criminalização do aborto, apresentando-se com a narrativa ficcional da obra literária a visualização de como uma sociedade pode se modificar rapidamente e restringir a liberdade e os direitos dos mais vulneráveis socialmente. Além da relevância social, o estudo também é importante cientificamente, em virtude da contribuição que alia literatura e direito com o objetivo de conferir uma perspectiva singular ao problema jurídico trabalhado, inquietar os leitores para o alerta apresentado na narrativa, e colaborar com a análise de uma temática delicada, mas essencial para o desenvolvimento de uma sociedade livre e igualitária.

Em relação à metodologia, optou-se pelo método dedutivo, analisando-se a narrativa ficcional apresentada e os direitos sexuais e reprodutivos, para alcançar o objetivo geral, que diz respeito à criminalização do aborto no Brasil e aos seus efeitos negativos para a saúde e liberdade das mulheres. No que tange à abordagem, o estudo é qualitativo, pois trabalha notadamente com significados e interpretações normativas, e, quanto aos objetivos, é descritivo e explicativo, visto que, além de registrar o contexto e as diferentes nuances em que se discute o aborto, também visa trazer interpretações do fenômeno jurídico. Utilizou-se um procedimento bibliográfico com dados provenientes de livros, artigos, além de normas constitucionais, infraconstitucionais e internacionais.

\section{0 conto da aia e a ausência de direitos das mulheres}

O Conto da Ala é uma obra literária de autoria da escritora canadense Margaret Atwood (2017), publicada originalmente em 1985 e que, desde então, foi adaptada para diversos formatos artísticos, tais como cinema, teatro, ópera e, mais recentemente, em abril de 2017 , para uma série de televisão. Atwood (2011) alerta que criou a história com base em diversos elementos reais, fatos que já aconteceram verdadeiramente, e classifica sua obra como uma ficção especulativa, pois é a idealização de algo concretizável (Cecília MANCUSO, 2016). Em diversos momentos históricos, por exemplo, os códigos de vestimenta, como retratados no livro, 
foram utilizados estrategicamente para identificar e controlar determinados grupos sociais, como ocorreu no nazismo, na Alemanha, quando se impôs a utilização de insígnias nas roupas e uniformes dos que eram perseguidos pelo regime, com destaque para a estrela amarela de Davi para os judeus, o triângulo rosa para os homossexuais e o triângulo vermelho para os comunistas (Jennifer VINEYARD, 2017).

A história se concentra na vida de uma personagem chamada Offred, que é concomitantemente a narradora, e que relata o sofrimento de ter perdido o marido, a filha, a liberdade e os direitos, em virtude de uma mudança radical que originou um novo modelo de Estado. Nesta toada, vislumbra-se uma sociedade ocidental livre e democrática, que se descobre, posteriormente, ter sido os Estados Unidos da América, e que, em virtude de um golpe de Estado, transforma-se na República de Gilead, submetida a um regime totalitário teocrático, imposto e liderado por um grupo de homens com a justificativa da resolução de uma crise de natalidade. Neste sentido, um desses comandantes esclarece que eles estavam pensando em fazer o melhor, mas que o "Melhor nunca significa melhor para todo mundo [...]. Sempre significa pior, para alguns" (ATWOOD, 2017, p. 251).

A alteração social ocorre em virtude de uma crise de natalidade na qual os índices de nascimento caíram vertiginosamente por diversos motivos, tais como epidemias de doenças como sífilis e AIDS, acidentes em usinas nucleares, vazamentos de armas químicas e biológicas e o uso descontrolado de inseticidas e substâncias químicas pulverizadas no ar, o que tornou a maioria das pessoas inférteis. Com a justificativa de resolver essa problemática e impedir a extinção da humanidade, um grupo de homens se organizou e decidiu impor uma nova organização estatal. Para tanto, assassinou o então Presidente da República, fechou o Congresso Nacional e suspendeu a Constituição. O Estado passou a controlar todos os aspectos das vidas das pessoas e, utilizando argumentos religiosos, eliminou os direitos das mulheres.

A nova formatação social tem como foco primordial evitar a extinção da humanidade mediante a obrigatoriedade da procriação e, com isto, justifica que os direitos das mulheres sejam totalmente suprimidos para que possam concentrar seus esforços para auxiliar a coletividade a alcançar o seu propósito. Foram, por isso, dispensadas de seus trabalhos, impedidas de acessar suas contas bancárias e possuir bens, que passaram a ser de propriedade dos cônjuges ou parentes mais próximos do sexo masculino. Além disso, foram proibidas de ler, estudar, ouvir música, se divertir etc., ou seja, não podiam fazer nada que não estivesse diretamente relacionado com aquilo para o qual eram designadas. Os homens, apesar de terem sua liberdade restringida, ainda possuíam direitos, continuando a trabalhar, ocupar cargos públicos e ter acesso à propriedade. As mulheres, que não eram mais titulares dos seus próprios corpos e destinos, foram divididas em castas, de acordo com o serviço que poderiam fornecer para o regime e, assim, suas atividades eram estritamente limitadas às funções que desempenhariam. A divisão delas também foi efetivada para que não se reunissem e se revoltassem contra o regime, uma vez que a paranoia de ser delatada por alguma atitude oposta aos padrões sociais era estimulada, tendo elas se tornado espiãs umas das outras. Desse modo, surgiram as aias, as marthas, as tias, as econoesposas, as esposas e as não mulheres.

As "aias" são as mulheres férteis que foram sequestradas pelo Estado, treinadas para fins reprodutivos e disponibilizadas para os altos comandantes do governo quando as mulheres destes fossem estéreis. Utilizam uma vestimenta vermelha com uma touca branca de abas largas para diminuir a visibilidade de seus rostos. As "marthas" são mulheres mais velhas ou jovens inférteis que desempenham funções de empregadas domésticas, limpando ou cozinhando nas casas das familias ricas e são identificadas pela vestimenta verde. As "tias" são mulheres mais velhas, inférteis, escolhidas pela sua crença na religião imposta ou para evitar serem enviadas para as colônias (campos de concentração); são elas que treinam as aias e, por isso, são respeitadas, sendo-lhes conferidos benefícios e poderes, visto que a melhor maneira de controlar um grupo é mediante a utilização de indivíduos pertencentes a este.

As "esposas" são as mulheres casadas com os altos comandantes do regime e são responsáveis pelo gerenciamento do lar e das aias que se encontram sob seu domínio; vestem azul e, pelo seu status mais elevado, podem costurar, tricotar, cuidar do jardim ou realizar alguma atividade considerada aceitável pela sociedade para ocupar o tempo. As "econoesposas" são as mulheres casadas com homens mais pobres e, por isso, têm que concentrar em si todas as funções, isto é, devem servir para fins reprodutivos e cuidar da casa e da família, por isso suas vestimentas são coloridas com listras vermelhas, azuis e verdes. Ressalta-se que os casamentos são todos arranjados, pois os relacionamentos entre as pessoas não se baseiam mais no afeto, mas apenas no que estes podem contribuir para o desenvolvimento da coletividade. As "não mulheres" são idosas, jovens que não conseguiram ser convertidas ao novo regime ou aias que não conseguiram reproduzir, e que, por não terem mais utilidade ao Estado, são enviadas para campos de concentração, nos quais trabalham de modo exaustivo e integral com a agricultura ou com a limpeza de lixos tóxicos, possuindo nestes uma estimativa de vida máxima de três anos. 
A narração tem como foco a história de uma mulher que, enquanto tenta fugir desse Estado totalitário com o marido e a filha, é sequestrada e transformada em uma aia, pois ainda é fértil. As aias perdem, inclusive, seus próprios nomes, pois passam a ser chamadas por um patronímico, assumido quando chegam à casa do comandante e abandonado quando a deixam. Desse modo, seus novos nomes são formados pela partícula "Of", no português "De", com o acréscimo do primeiro nome do comandante para o qual presta o serviço. A protagonista da história é chamada de "Offred", isto é, "De Fred". Portanto, até o nome representa a sua categorização como propriedade, perdendo a mulher toda a individualidade que a caracteriza como ser humano.

Elas, então, são destituídas de tudo o que possuem e enviadas para centros de treinamento, nos quais, após uma intensa intervenção comportamental e psicológica, com a frequente utilização de violência, tortura, manipulação e distorção da realidade, realizada pelas tias, são convertidas aos novos padrões sociais, aprendendo os serviços que irão desempenhar e como devem se comportar. As "tias" argumentam que elas foram escolhidas por Deus para exercer uma função importante na sociedade, pois são as responsáveis pelo futuro desta mediante a reprodução e que devem encarar suas atividades como missões divinas e, por isso, serem gratas. Algumas são efetivamente convertidas, outras apenas se conformam com a situação, pois não têm poder ou força para modificá-la, enquanto que outras cometem suicídio por não suportarem a submissão.

Depois de passarem pelo centro de treinamento e se tornarem aias, são enviadas para as casas de altos comandantes do Estado cujas esposas não conseguem engravidar, onde vivem como servas sexuais, disponíveis para fins estritamente reprodutivos. Para tanto, participam periodicamente de uma cerimônia, na tentativa de gerar uma criança para o casal para o qual foram designadas. A cerimônia consiste na leitura de trechos da Bíblia pelo comandante a todos os membros da família e funcionários da casa, e depois este, sua esposa e a aia se dirigem ao quarto do casal, no qual esta se deita na cama entre a esposa e o comandante, e este deposita seu sêmen na aia, mediante o método tradicional de fertilização.

O processo é um exemplo da violação de direitos que se torna legalmente imposta em virtude do regime autoritário da República de Gilead e que demonstra notadamente a função reprodutiva que as mulheres representam para essa estrutura social. A cerimônia é encarada como um serviço no qual todos estão cumprindo seus deveres, porém, o ônus para as mulheres é desproporcionalmente maior, pois não tiveram condições efetivas de escolha, funcionando apenas como receptáculos, visto que "[...] somente as entranhas de nossos corpos é que são consideradas importantes" (ATWOOD, 2017, p. 1 18), existindo apenas "[...] para fins de procriação: não somos concubinas, garotas gueixas, cortesãs. [...] Somos úteros de duas pernas, apenas isso: receptáculos sagrados, cálices ambulantes (ATWOOD, 2017, p. 165). A presença da esposa no ritual simboliza o vínculo que possui com a serva, como se o marido a estivesse engravidando por meio da aia, pois esta fica posicionada com a cabeça entre as pernas da esposa, que a segura pelos braços. Para tanto, o grupo religioso se baseia em uma passagem da bíblia cristã:

\footnotetext{
Vendo que não dava filho a Jacó, Raquel ficou com inveja de sua irmã e disse a Jacó: 'Ou você me dá filhos ou eu morro'. Jacó ficou irritado com Raquel, e disse: 'Por acaso eu sou Deus para Ihe negar a maternidade?'. Raquel respondeu: 'Aqui está minha serva Bala. Una-se a ela, para que ela dê à luz sobre os meus joelhos. Assim terei filhos por meio dela'. Então Raquel lhe deu sua serva Bala como mulher, e Jacó uniu-se a Bala. Bala concebeu e deu à luz um filho para Jacó (BÍBLIA, Gênesis, 30:1-5, 2005, p. 43).
}

A aia produzirá e amamentará a criança, mas não terá nenhum vínculo afetivo com esta. A sua estadia com a família é delimitada temporalmente e, tendo ou não gerado o fruto pretendido, após o período de dois anos, é designada para outra casa e, assim, sucessivamente, por até três vezes. Se, ao final destas tentativas, não conseguir reproduzir, será enviada para as colônias, pois não conseguiu atender ao propósito que lhe foi destinado. Algumas não suportam o ônus do serviço e se suicidam.

Ao longo de toda a circunscrição do distrito onde se passa a história, existem postos de controle, com soldados armados para a proteção e manutenção da ordem social. Há também um muro onde subversivos mortos são expostos para serem vistos pelo maior número de pessoas, e servirem como exemplo do que é feito com aqueles que tentam subverter o sistema. Diz-se que há uma guerra em curso, mas como ninguém tem acesso a múltiplos canais de informações, aquelas que são televisionadas podem ter sido fabricadas ou, no mínimo, manipuladas pelo governo. Também fecharam as universidades, impedindo a construção e o acesso ao conhecimento.

De um modo geral não há liberdade, inclusive para os homens, mas como o problema da sociedade é a redução de nascimentos e, em tese, são as mulheres que o podem solucionar, são elas as escolhidas para terem suas vidas cerceadas. Além disso, predomina um fundamentalismo religioso patriarcal que se baseia em preceitos bíblicos, e, assim, mesmo as mulheres que não conseguem reproduzir devem se submeter aos ordenamentos das figuras masculinas às quais 
estão relacionadas, e agir de acordo com padrões sociais compreendidos como os ideais para o seu gênero, por isso, suas atividades se resumem basicamente ao cuidado do ambiente doméstico e dos filhos. Desse modo, aquelas que não podem ou não conseguem ser forçadas a se conformar ao exercício destas funções são enviadas para campos de concentração e denominadas de "não mulheres".

Pode-se dizer que as mulheres dessa sociedade são escravas, pois seus corpos e existências não Ihes pertencem mais, servindo apenas a um propósito a que elas não tiveram liberdade para escolher. Perderam a individualidade, a autonomia, o domínio sobre os seus destinos, e foram transformadas em objetos, instrumentos com objetivos e funções específicas predeterminadas a serem desempenhadas na sociedade. Neste ponto, é relevante a recordação da aia sobre a sua vida anterior:

Eu costumava pensar em meu corpo como um instrumento de prazer, ou um meio de transporte, ou um implemento para a realização de minha vontade. Eu podia usá-lo para correr, para apertar botões, deste ou daquele tipo, fazer coisas acontecerem. Havia limites, mas meu corpo era, apesar disso, flexível, único, sólido, parte de mim (ATWOOD, 2017, p. 90).

Com esse breve resumo da narrativa, vislumbra-se uma realidade na qual as mulheres foram escolhidas para serem destituídas da liberdade e de seus direitos, se tornando objetos com propósitos previamente delineados sob o argumento de resolução de uma crise. A obra retrata uma sociedade sem liberdade, na qual as mulheres não são titulares nem mesmo dos seus próprios corpos, não podendo decidir sobre nada que lhes diga respeito, devendo apenas obedecer a uma predeterminação sobre a qual não foram sequer consultadas.

Traz-se esta narrativa literária como um mecanismo de alerta para o que, em níveis extremos, pode acontecer com as minorias sociais quando estas não participam, ou são impedidas de participar, dos processos que decidem o rumo da sociedade em que vivem. É possível estabelecer um paralelo da história com a realidade de países que vivem sob regimes ditatoriais religiosos como, por exemplo, a Arábia Saudita, que só permitem às mulheres casar, abrir uma conta bancária, viajar para o exterior, por exemplo, com a autorização de seus guardiões, que são tutores do sexo masculino. Além disso, ainda há a restrição de uso de vestimentas que fazem com que precisem se cobrir completamente para se locomoverem em locais onde há a presença de homens (BBC, 2017). No Afeganistão, há o costume de se referir às mulheres apenas como mães, filhas ou esposas de um indivíduo do sexo masculino, ou seja, seus nomes não são mencionados, pois estes, assim como o corpo delas, enquanto elementos de suas identidades, pertencem aos homens aos quais estão vinculadas (Mujib MASHAL, 2017).

No entanto, também é possível relacionar a história narrada com a realidade brasileira, na qual prevalece um Estado Democrático de Direito que formalmente prima pela igualdade e a liberdade de seus cidadãos. Isso porque, no Brasil, as mulheres sofrem cotidianamente com discriminação, pois são a maioria desempregada da população, recebem, no geral, cerca de $76 \%$ da remuneração paga aos homens (IBGE, 2016), e são vítimas de violência rotineira tanto em ambientes públicos quanto privados (BRASIL, 2015). Além destas situações, que as impedem de viver com dignidade, não possuem também liberdade para decidir sobre o que acontece com seus próprios corpos, uma vez que quando engravidam e, portanto, estão sujeitas a todas as implicações e riscos de uma gestação, não podem escolher se continuam ou não com a gravidez, já que o aborto é criminalizado, sendo possível somente em situações excepcionais. Portanto, no próximo tópico, o aborto será analisado como um instrumento de liberdade para a mulher e a sua criminalização, uma forma de controle e restrição desta. Neste ponto, semelhante às mulheres do livro O Conto da Aia, as brasileiras, restringidas nos seus direitos reprodutivos, também não podem decidir se desejam ou não reproduzir, pois há uma imposição legislativa que as impede de escolher.

\section{Direitos reprodutivos e a criminalização do aborto no Brasil}

O termo "direitos reprodutivos" foi originalmente elaborado pelos movimentos feministas no final da década de 1970, nos Estados Unidos, com enfoque nas temáticas relativas ao aborto e aos anticoncepcionais, e difundido para o restante do mundo mediante encontros internacionais como, por exemplo, o I Encontro Internacional de Saúde da Mulher de 1984, que ocorreu em Amsterdã, no qual o termo foi utilizado oficialmente pela primeira vez (Myriam ALDANA; Silvana WINKLER, 2009, p. 170). Contudo, a consolidação de tais direitos só ocorreu após dez anos, na Conferência Internacional de População e Desenvolvimento de 1994, na cidade do Cairo. No capítulo VII do relatório proveniente deste encontro, há a definição de direitos reprodutivos:

7.3. [...] Esses direitos se baseiam no reconhecido direito básico de todo casal e de todo indivíduo de decidir livre e responsavelmente sobre o número, o espaçamento e a oportunidade de seus filhos e de ter a informação e os meios de assim o fazer, e o direito de gozar do mais alto padrão de saúde sexual e de reprodução. Inclui também seu direito de tomar decisões sobre a 
reprodução, livre de discriminação, coerção ou violência, conforme expresso em documentos sobre direitos humanos (ONU, 1994, p. 62).

No ano seguinte, em Pequim, realizou-se a IV Conferência Mundial sobre a Mulher, na qual os direitos reprodutivos foram destacados, conferindo um enfoque maior à liberdade sexual e reprodutiva. No documento originado desta conferência há menção expressa aos direitos humanos das mulheres e que estes incluem o "[...] controle sobre as questões relativas à sua sexualidade, inclusive sua saúde sexual e reprodutiva, e a decidir livremente a respeito dessas questões, livres de coerção, discriminação e violência [...]" (ONU, 1995, p. 179). Em ambos os encontros, estabeleceu-se como meta o combate aos abortos inseguros, que consistem em um problema de saúde pública, uma vez que colocam em risco a vida das mulheres, principalmente das mais pobres, que já se encontram em condição de vulnerabilidade social e que, em virtude desta, se submetem a abortos realizados por pessoas sem competência ou em ambientes desprovidos dos mínimos padrões médicos adequados. Neste sentido, devem os Estados se esforçar para tratar as sequelas e complicações decorrentes de abortos, no intuito de reduzir a mortalidade de mulheres.

Nos documentos internacionais acima referidos, os Estados se comprometeram em adotar medidas para garantir a liberdade reprodutiva, com um sistema de saúde que englobe serviços mais adequados, com informações e instrumentos de prevenção e auxílio, e métodos mais eficazes e não coercitivos no que tange ao planejamento familiar e ao controle de fecundidade, para que os indivíduos possam ser livres para vivenciar saudavelmente a sua sexualidade e decidir com autonomia a respeito da reprodução. Além destas, destaca-se também a revisão da legislação nacional para uma garantia e proteção mais incisiva dos direitos à saúde das mulheres, tratando, inclusive, das complicações provenientes de abortos, e considerando a possibilidade de rever as normas que prevejam "[...] medidas punitivas contra as mulheres que se tenham submetido a abortos ilegais" (ONU, 1995, p. 183), devendo elas receber orientação e tratamento humanitário.

Percebe-se que tais eventos internacionais consideram a reprodução e a sexualidade como direitos humanos, na medida em que as vislumbram como dimensões essenciais da existência dos indivíduos, reconhecendo a necessidade de proteger a liberdade no exercício destes, tanto para homens como para mulheres, e devendo ser analisados sob uma perspectiva de igualdade entre estes. Ressalta-se que o Brasil assinou tais documentos, assumindo assim um compromisso quanto ao seu cumprimento. Para Sônia Corrêa e Rosalind Petchesky (1996, p. 149), os direitos reprodutivos abrangem diversos aspectos:

Definimos o terreno dos direitos sexuais e reprodutivos em termos de poder e recursos: poder de tomar decisões com base em informações seguras sobre a própria fecundidade, gravidez, educação dos filhos, saúde ginecológica e atividade sexual; e recursos para levar a cabo tais decisões de forma segura. Este terreno envolve necessariamente as noções sobre 'integridade corporal' ou 'controle sobre o próprio corpo'. No entanto, também estão em questão as relações que se tem com filhos, parceiros sexuais, membros da família, a comunidade e a sociedade como um todo. Em outras palavras, o corpo existe em um universo socialmente mediado.

Em relação às mulheres, percebe-se que tais direitos refletem a autonomia no cuidado com os seus próprios corpos, o que abrange as decisões individuais que os envolvem, de modo que possam deliberar livremente sobre como vivenciar e expressar suas sexualidades e reprodução, possibilitando-as controlar o que acontece nas suas vidas. Libertando-as de padrões sociais que as restringem a uma única função na sociedade, notadamente a maternidade, às mulheres deve ser facultado escolher o rumo e os objetivos que desejam traçar e alcançar, da mesma forma como os homens sempre fizeram. Contudo, para se tornarem efetivos, referidos direitos precisam de condições concretas que possibilitem o seu exercício e, para tanto, são necessárias políticas públicas específicas que trabalhem com a saúde da mulher na prevenção e resolução de problemas, mediante a disponibilização de métodos contraceptivos, de planejamento familiar, de proteção contra doenças sexualmente transmissíveis, bem como de mecanismos seguros para a realização de abortamentos.

Analisando a etimologia, "[...] a palavra aborto deriva do latim 'abortus'. 'Ab' significa privação e 'ortus' significa nascimento. Portanto, quanto ao étimo, aborto significa privação do nascimento [...]" (Ivanildo ALVES, 1999, p. 193). Assim, pode-se definir aborto como a interrupção do processo gestacional com a morte do produto deste. Pode ser espontâneo, quando ocorre em virtude de condições naturais, ou seja, sem interferência humana; ou provocado, quando um indivíduo executa atos específicos para interromper a gestação, eliminando o que estaria sendo produzido nela, estando neste momento configurado o crime, de acordo com a legislação penal adotada no Brasil. Neste artigo, analisa-se a criminalização do aborto provocado no ordenamento jurídico brasileiro.

A prática do aborto sempre esteve presente na história da humanidade; a distinção está na forma como é tratada, ora havendo a liberação, ora a criminalização da conduta. Na Grécia antiga, era um procedimento comum, não havendo divergências profundas sobre o tema. 
O direito romano não a entendia como comportamento criminoso, pois admitia que o feto integrava o corpo da gestante, podendo ela dispor livremente deste, e foi condenado no Código de Hamurabi por influências religiosas (Rachelle BALBINOT, 2003). Assim, sempre existiram mulheres que não estavam dispostas a dar continuidade à gestação e optavam por interrompê-la antes do seu término; o que variava e varia até hoje é o modo como esta vontade é qualificada por aqueles que elaboram as regras que organizam a sociedade. A prevalência de ideais religiosos que compreendem a vida como um bem divino e, portanto, sagrado, que não pode estar submetido à livre disposição dos seres humanos, bem como a decisão sobre a sua continuidade, com a consequente defesa da vida intrauterina, faz com que o aborto, em alguns países, seja considerado uma conduta típica, punível pelo direito penal.

No Brasil, o aborto foi criminalizado desde a origem do Estado, com previsão expressa no Código Criminal do Império de 1830, depois no Código Penal Republicano de 1890 e, finalmente, no Código Penal de 1940 (BRASIL, 1940), sendo que o texto relativo ao referido ilícito permanece o mesmo desde a sua criação até os dias atuais. Neste, o aborto encontra-se tipificado no título "Dos crimes contra a pessoa", no capítulo "Dos crimes contra a vida", com previsão nos artigos 124 a 128.

Os artigos do Código Penal trazem quatro modalidades de aborto: o que é realizado pela própria gestante, praticando esta os atos de interrupção da gestação e destruição do feto; o provocado por terceiro, que pode ser praticado por qualquer pessoa com ou sem o consentimento da gestante; o necessário, realizado por um médico para salvar a vida da gestante, quando não há outra maneira de fazê-lo, não sendo, por isso, considerado crime, visto que o legislador optou por preservar a vida de um ser já formado em face de outro que ainda estava em desenvolvimento; e o autorizado, quando a gravidez resulta de estupro, compreendendo-se que não se pode exigir da mulher que permaneça com o fruto de um ato que a violentou. Em todas estas categorias, "O núcleo do tipo penal das modalidades abortivas é o verbo provocar, que tem o sentido de ocasionar, promover, estimular, produzir, dar causa, originar [...]" (ALVES, 1999, p. 200).

A legislação não faz distinção entre o óvulo fecundado (até as três primeiras semanas), o embrião (até os três primeiros meses) e o feto (a partir do terceiro mês), estando configurado o crime em qualquer destas fases gestacionais (Nelson HUNGRIA; Cláudio Heleno GRAGOSO, 1981). Entende-se que a vida começa a partir da fertilização do óvulo feminino pelo espermatozoide masculino, mas que a proteção penal só incide a partir da fixação do óvulo fecundado na parede do útero (Fernando CAPEZ, 2015). A criminalização do aborto visa proteger a vida intrauterina, pois, apesar da personalidade civil da pessoa só se originar com o nascimento com vida, os direitos do nascituro já estariam salvaguardados, de acordo com o artigo 20, do Código Civil de 2002 (BRASIL, 2002), e conforme o artigo $4^{\circ}$ do Código Civil de 1916 (BRASIL, 1916), que estava em vigor na época da elaboração do Código Penal.

Adicionando uma exceção jurisdicional à criminalização legal, o Supremo Tribunal Federal, em abril de 2012, ao julgar a Ação de Descumprimento de Preceito Fundamental n 54, declarou que a interrupção da gravidez de feto anencefálico não configura nenhuma das condutas previstas nos artigos 124 a 128 do Código Penal, sendo, portanto, possível de ser praticada sem que seja caracterizada como crime. Embora este caso se refira especificamente à possibilidade do aborto nos casos em que o feto possui ínfimos índices de sobrevivência após uma gestação completa, destaca-se partes do voto do ministro relator, Marco Aurélio de Mello, no qual defende a autonomia, vida e saúde reprodutiva das mulheres, sendo possível estender seu argumento para a defesa do aborto mesmo nos casos em que não haja anencefalia:

Está em jogo o direito da mulher de autodeterminar-se, de escolher, de agir de acordo com a própria vontade num caso de absoluta inviabilidade de vida extrauterina. Estão em jogo, em última análise, a privacidade, a autonomia e a dignidade humana dessas mulheres. Hão de ser respeitadas tanto as que optem por prosseguir com a gravidez - por sentirem-se mais felizes assim ou por qualquer outro motivo que não nos cumpre perquirir - quanto as que prefiram interromper a gravidez, para por fim ou, ao menos, minimizar um estado de sofrimento. [...] Vale ressaltar caber à mulher, e não ao Estado, sopesar valores e sentimentos de ordem estritamente privada, para deliberar pela interrupção, ou não, da gravidez. Cumpre à mulher, em seu íntimo, no espaço que Ihe é reservado - no exercício do direito à privacidade -, sem temor de reprimenda, voltar-se para si mesma, refletir sobre as próprias concepções e avaliar se quer, ou não, levar a gestação adiante. Ao Estado não é dado intrometer-se. [...] Os tempos atuais, realço, requerem empatia, aceitação, humanidade e solidariedade para com essas mulheres. [...] somente aquela que vive tamanha situação de angústia é capaz de mensurar o sofrimento a que se submete. Atuar com sapiência e justiça, calcados na Constituição da República e desprovidos de qualquer dogma ou paradigma moral e religioso, obriga-nos a garantir, sim, o direito da mulher de manifestar-se livremente, sem o temor de tornar-se ré em eventual ação por crime de aborto (grifos nossos) (BRASIL, STF, ADPF n 54, 2012).

Apesar da criminalização da conduta, o número de abortos praticados ilegalmente no Brasil não diminui. De acordo com a pesquisa nacional de aborto (Debora DINIZ; Marcelo MEDEIROS; 
Alberto MADEIRO, 2016), de um total de 2.002 mulheres com idade entre 18 e 39 anos que foram entrevistadas, cerca de 251 já fizeram pelo menos um aborto, o que representa um percentual de 13\%, ou seja, aproximadamente uma em cada cinco brasileiras já fez pelo menos um aborto até os 40 anos de idade. Aplicando esse percentual à quantidade de mulheres alfabetizadas nessa faixa etária, a pesquisa conclui que, em 2015, 503 mil mulheres abortaram pelo menos uma vez. Metade destas utilizou medicamentos para a prática do ato, e, a partir de dados da rede pública de saúde, metade delas precisou ser internada para finalizar o procedimento. Destaca-se que a prática do aborto é realizada por mulheres (DINIZ; MEDEIROS; MADEIRO, 2016, p. 656):

a) de todas as idades (ou seja, permanece como um evento frequente na vida reprodutiva de mulheres há muitas décadas); b) casadas ou não; c) que são mães hoje; d) de todas as religiões, inclusive as sem religião; e) de todos os níveis educacionais; f) trabalhadoras ou não; g) de todas as classes sociais; h) de todos os grupos raciais; i) em todas as regiões do país; j) em todos os tipos e tamanhos de município.

Não há, portanto, um perfil específico de mulheres que recorrem aos procedimentos abortivos, uma vez que a conduta abrange diversas faixas etárias, religiões, classes sociais e grupos raciais, sendo, portanto, uma prática corriqueira de mulheres comuns. Verifica-se também que os dados da pesquisa de 2016 não se alteraram com discrepância relevante em relação aos obtidos em 2010, concluindo-se que a ilegalidade do ato não o impede de ser praticado. O impedimento legal do procedimento apenas o torna mais perigoso, já que é realizado na clandestinidade, por pessoas inábeis, em ambientes anti-higiênicos e sem a utilização e observância de métodos adequados que garantam a proteção à vida e à saúde das mulheres. Por isso, os índices de mortalidade em decorrência de complicações do aborto são altos quando há a proibição. No Brasil, diariamente, quatro mulheres morrem em virtude de complicações decorrentes de abortos, totalizando, em 2015, 1.664 mortes de mulheres nessas circunstâncias (Lígia FORMENTI, 2016).

Neste sentido, um estudo realizado pela Organização Mundial de Saúde demonstrou que a proibição do aborto não evita que este ocorra e que os riscos pela realização de abortos inseguros são maiores nos países em que são total ou parcialmente proibidos, como no Brasil. Os riscos são insignificantes quando os procedimentos abortivos são permitidos e realizados de acordo com os ditames previstos pela referida organização. O estudo também concluiu que o acesso ao aborto, aliado a políticas públicas de educação sexual, contracepção e planejamento familiar, faz com que os índices de aborto diminuam (OMS, 2017), contrariando o senso comum da população que tem a falsa percepção de que a liberação geraria um aumento e descontrole total na realização dos procedimentos abortivos.

Verifica-se que o desejo das mulheres em interromperem suas gestações sempre existiu e que, quando querem, elas o fazem, sendo ou não esta conduta considerada proibida. A diferença é que os abortos clandestinos e, consequentemente, inseguros à vida e à saúde da mulher, aumentam quando há a proibição legal, e diminuem quando esta não existe. Assim, tratase notadamente de uma questão de saúde pública e que, portanto, não deve ser enfrentada sob uma perspectiva religiosa ou moralista. Quanto mais se proíbe o aborto, mais alta é a probabilidade de as mulheres morrerem em decorrência da insegurança dos métodos adotados nos abortamentos. Resta, portanto, saber qual deve preponderar, a vida ou a liberdade da mulher já existente ou a vida de um ser ainda em desenvolvimento. A resposta para tal indagação envolve a colisão de direitos fundamentais, e pode ser política, com a alteração da legislação vigente, permitindo-se a realização do aborto, ou jurisdicional, com o ajuizamento da ação respectiva.

Em novembro de 2016, o Supremo Tribunal Federal reacendeu a discussão sobre a legalização do aborto, ao julgar o Habeas Corpus n 124.306, impetrado contra a prisão preventiva de denunciados pelo Ministério Público do Rio de Janeiro pela prática do crime de aborto com consentimento da gestante. Além de considerar que não estavam preenchidos os requisitos para a prisão cautelar, o ministro Luís Roberto Barroso argumentou ser necessário interpretar os artigos do Código Penal que criminalizam o aborto à luz da Constituição de 1988, para:

[...] excluir do seu âmbito de incidência a interrupção voluntária da gestação efetivada no primeiro trimestre. A criminalização, nessa hipótese, viola diversos direitos fundamentais da mulher, bem como o princípio da proporcionalidade. 4. A criminalização é incompatível com os seguintes direitos fundamentais: os direitos sexuais e reprodutivos da mulher, que não pode ser obrigada pelo Estado a manter uma gestação indesejada; a autonomia da mulher, que deve conservar o direito de fazer suas escolhas existenciais; a integridade física e psíquica da gestante, que é quem sofre, no seu corpo e no seu psiquismo, os efeitos da gravidez; e a igualdade da mulher, já que homens não engravidam e, portanto, a equiparação plena de gênero depende de se respeitar a vontade da mulher nessa matéria (grifos originais) (BRASIL, STF, HC 124.306, 2016, p. 01).

Na hipótese relativa ao aborto, pode-se verificar a colisão entre direitos fundamentais, quais sejam, o direito à vida do feto e os direitos sexuais e reprodutivos, de autonomia e integridade física e psíquica da mulher, que preveem consequências contraditórias entre si, visto que o primeiro proibiria a realização de procedimentos abortivos para a proteção da vida intrauterina e os demais 
permitiriam a execução do aborto para garantir a liberdade e a saúde da mulher. De acordo com Robert Alexy (2015), enquanto princípios, e abstratamente considerados, os direitos fundamentais possuem pesos equivalentes, não existindo precedência de um sobre o outro. Porém, diante de um caso concreto, as circunstâncias deste fazem com seja possível atribuir pesos diferenciados aos direitos, e aquele que possuir o maior peso, se houver razões suficientes para tanto, prevalecerá naquela situação fática específica. Para a realização do sopesamento, o referido autor utiliza o princípio da proporcionalidade, que possui três máximas parciais: a adequação, a necessidade e a proporcionalidade em sentido estrito. Esta argumentação racional foi utilizada pelo ministro na referida decisão judicial.

Ao analisar a íntegra do voto proferido pelo ministro, verifica-se que este examina a constitucionalidade da criminalização do aborto nos três primeiros meses de gestação. Explica inicialmente que, para uma conduta ser tipificada criminalmente e estar em compatibilidade com a Constituição, é preciso a demonstração de que há um bem jurídico relevante a ser protegido, que a conduta não represente o exercício de um direito fundamental e que haja a devida proporção entre o ato praticado e a reação do Estado com a tipificação deste. Nesse sentido, declara que a vida do feto é relevante para ser protegida, mas que a proibição legal dos procedimentos abortivos nesse período viola diversos direitos fundamentais das mulheres, não configurando uma resposta proporcional do Estado em face da conduta do particular.

Afirma que existe divergência a respeito da compreensão sobre o início da vida, pois, para alguns, este se daria com a fecundação do óvulo pelo espermatozoide, e, para outros, somente ocorreria com a formação do sistema nervoso central, que geralmente ocorre após o terceiro mês do processo gestacional. E que, por não haver um entendimento uníssono, a escolha de qual adotar deve ser individual. No entanto, independente de qual opção seja adotada, é inquestionável o fato de que até o terceiro mês de gestação não há possibilidade de sobrevivência para o embrião fora do útero, prescindindo este completamente do organismo feminino.

Sabe-se que os direitos fundamentais surgiram para proteger os indivíduos contra as arbitrariedades estatais, garantindo a liberdade individual pela abstenção do Estado nas relações entre aqueles. São, por isso, oponíveis em face do próprio Estado e, inclusive, contra o legislador, pois são consideradas cláusulas pétreas, de acordo com o artigo 60, §4०, da Constituição. Na decisão, o ministro analisa os diversos direitos fundamentais das mulheres que são diretamente violados pela criminalização do aborto.

O ministro define autonomia como "[...] o núcleo essencial da liberdade individual, protegida pelo principio da dignidade humana [...], expressa a autodeterminação das pessoas, isto é, o direito de fazerem suas escolhas existenciais básicas [...]". Especificamente para a mulher, relaciona-se com a possibilidade de "[...] controlar o próprio corpo e de tomar as decisões a ele relacionadas, inclusive a de cessar ou não uma gravidez". E questiona como poderia o Estado impor uma gravidez a uma mulher, tratando-a como se fosse "[... ] um útero a serviço da sociedade [...]" e não como um indivíduo pleno e autônomo (BRASIL, 2016, p. 09).

A integridade física e psíquica da mulher também estaria sendo violada, pois a garantia contra indevidas restrições ao seu organismo seria impactada por uma gravidez indesejada que promove, contrariamente à sua vontade, alterações físicas e psíquicas, além da pressão pela responsabilidade futura na criação e cuidado de uma vida, após o nascimento desta. Há a violação dos direitos sexuais e reprodutivos da mulher, que incluem a liberdade na decisão sobre a reprodução. A igualdade de gênero, que proíbe tratamentos injustificadamente desequilibrados, estaria também prejudicada, pois como são as mulheres as únicas que engravidam e sofrem com as alterações decorrentes desta, apenas a elas cabe a decisão da continuidade ou não do processo gestacional. Além disso, a proibição legal do aborto também gera discriminação social, pois prejudica, desproporcionalmente, as mulheres mais pobres que, por não possuírem condições econômicas suficientes, se submetem a situações ainda mais precárias e inseguras nos procedimentos abortivos clandestinos.

Após demonstrar que a criminalização do aborto viola os direitos fundamentais das mulheres, o ministro afirma que também há ofensa ao princípio da proporcionalidade, pois, para uma conduta ser transformada em crime, é preciso que o legislador obedeça às normas constitucionais. Analisa os três subprincípios da proporcionalidade para a constatação da desproporção da proibição legal da intervenção voluntária da gestação.

Para que a adequação estivesse garantida, a criminalização do aborto teria que ser a medida mais adequada para a proteção da vida do feto, o que não corresponde com a realidade, uma vez que é ineficaz para alcançar o objetivo pretendido, qual seja, de impedir que os abortos sejam realizados. Pelo contrário, a proibição, além de não conseguir proteger a vida intrauterina, apenas prejudica a vida e a saúde das mulheres, que precisam se submeter a procedimentos clandestinos inseguros. No que tange à necessidade, deve-se verificar se não haveria uma medida alternativa à proibição legal que fosse menos gravosa aos direitos das mulheres e que conseguisse alcançar o objetivo almejado de proteção à vida do feto. Para tanto, pode-se citar a descriminalização do aborto nos primeiros meses de gestação, e o investimento em políticas públicas de educação 
sexual, de assistência especializada à saúde da mulher, com aconselhamento sobre planejamento familiar e a ampliação do acesso aos métodos contraceptivos.

Na proporcionalidade em sentido estrito, quando há o sopesamento dos interesses em colisão, verificando-se qual deles deve prevalecer, conclui que referida proibição viola diversos direitos das mulheres e que promove um grau reduzido, se não ínfimo, de proteção à vida do feto, pela incapacidade de se impedir que os abortos continuem acontecendo, não havendo, portanto, a devida compensação para que fosse legítima a restrição aos direitos. Neste ponto, afirma que "[...] o peso concreto do direito à vida do nascituro varia de acordo com o estágio de seu desenvolvimento na gestação. [...] ampliado na medida em que a gestação avança e que o feto adquire viabilidade extrauterina [...]" (BRASIL, 2016, p. 16). Portanto, até os três meses do processo gestacional, a vida e os direitos da mulher preponderariam sobre o direito do feto. Conclui que:

Sopesando-se os custos e benefícios da criminalização, torna-se evidente a ilegitimidade constitucional da tipificação penal da interrupção voluntária da gestação, por violar os direitos fundamentais das mulheres e gerar custos sociais (e.g., problema de saúde pública e mortes) muito superiores aos benefícios da criminalização (BRASIL, STF, HC 124.306, 2016, p. 16).

Portanto, os artigos do Código Penal referentes ao aborto devem ser interpretados à luz da Constituição de 1988 para que se compreenda que os procedimentos abortivos, nos primeiros meses da gestação, não devem ser criminalizados, e "[...] como o Código Penal é de 1940 [...] e a jurisprudência do STF não admite a declaração de inconstitucionalidade de lei anterior à Constituição, a hipótese é de não recepção [...] dos dispositivos apontados do Código Penal" (BRASIL, 2016, p. 17).

Entende-se, por conseguinte, que as mulheres, antes de serem vistas inerentemente como reprodutoras, devem ser vislumbradas como seres humanos, como cidadãs que devem poder decidir com autonomia se desejam ou não se tornarem mães. O Estado deve atuar mediante políticas públicas para garantir a vida e a saúde tanto para as mulheres que desejam como para aquelas que não desejam reproduzir, disponibilizando os instrumentos adequados para tanto. Compreende-se que o feto deve ser protegido, mas que até o terceiro mês de gestação, a sua vida em desenvolvimento não tem o mesmo peso que a vida da genitora que deve estar em pleno gozo de seus direitos e liberdades. De acordo com o Ministério da Saúde (BRASIL, 2001, p. 15),

A reprodução afeta a mulher de uma forma que transcende as divisões de classe e permeia todas as suas atividades: sua educação, seu trabalho, seu envolvimento político e social, sua saúde, sua sexualidade, enfim, sua vida e seus sonhos. É necessário que se deixe de romantizar o poder que pode existir da conexão biológica da mulher com a maternidade. É fundamental deixar de subestimar o poder repressivo sobre as mulheres que se estabelece com essa conexão. Pois essa visão 'reprodutiva' das mulheres é muito menos o resultado de sua condição biológica e, acima de tudo, determinada pela organização social e cultural. E não se pode deixar de reconhecer que essa organização tem, até hoje, buscado cercear os esforços das mulheres para ganhar um pouco de espaço de controle sobre suas vidas e seus corpos e para expressar livremente sua sexualidade.

A sociedade brasileira deve encarar as temáticas analisadas no artigo como questões de saúde pública, vislumbrando o aborto como um instrumento a ser adotado de forma excepcional, mas possível e legal até o terceiro mês da gravidez, uma vez que permite à mulher escolher livremente se deseja ou não dar continuidade à gestação e, consequentemente, à maternidade, permitindo que esta seja almejada e não uma imposição social pelo simples fato de ser mulher, desvinculando-a de padrões sociais de gênero que restringem a sua vida, possibilitando que haja a escolha de não querer reproduzir, ou, se querendo, que o ser humano gerado seja desejado e bem-vindo ao mundo que o espera.

O livro O conto da aia, relatado no início do artigo, apesar de ser oficialmente uma ficção, não retrata uma história distante da realidade brasileira, pois assim como na República de Gilead, no Brasil, com a proibição do aborto, às mulheres ainda se impõe um ônus reprodutivo que restringe os direitos destas, limitando a livre existência e o domínio sobre seus próprios corpos. Por isso, para evitar que os direitos dessa parcela majoritária da população padeçam ainda mais, a sociedade brasileira deve considerar as pesquisas que já foram realizadas sobre a interrupção voluntária da gestação, bem como atentar para os ordenamentos internacionais dos quais o Brasil é signatário, para que haja uma modificação na legislação, que permanece a mesma desde 1940, não atende às necessidades da realidade brasileira e não está de acordo com as normas constitucionais.

As questões abordadas neste artigo vinculam-se especificamente aos direitos das mulheres, sendo, portanto, indispensável que estas estejam diretamente envolvidas no debate, seja como agentes decisórios, preferencialmente, criando políiticas públicas adequadas, seja como pessoas a serem ouvidas para a construção destas, uma vez que é inadmissível que decisões que envolvem e repercutem no corpo delas sejam resolvidas sem a sua presença ativa. No Brasil, a ínfima 
participação das mulheres na política institucional (cerca de 10\% na Câmara dos Deputados e 14\% no Senado Federal), desproporcional à maioria da população feminina brasileira, permite que homens decidam sobre as questões que impactam nos direitos das mulheres, sem que estas sejam sequer ouvidas.

Isso pôde ser constatado recentemente pela aprovação, na Comissão Especial da Câmara dos Deputados, de uma proposta de emenda ao texto constitucional (PEC no 181/2015) que visa incluir na Constituição a expressão "desde a concepção" como complemento ao direito à vida (Lara HAJE, 2017). Se esta alteração for aprovada, após a observância dos trâmites legislativos típicos de uma emenda constitucional, a vida será constitucionalmente protegida desde a fecundação do óvulo pelo espermatozoide, o que dificultará não apenas o debate a respeito da legalização do aborto, pois a vida intrauterina terá o mesmo peso daquela já concebida e desenvolvida, mas também da realização dos procedimentos abortivos atualmente autorizados pela legislação penal (para salvar a vida da gestante e nos casos de gravidez decorrente de estupro), visto que, sendo a Constituição norma hierarquicamente superior, deve servir de fundamento para todo o restante do ordenamento jurídico. Ressalta-se que, na referida comissão legislativa, de um total de dezenove membros, havia apenas uma mulher, que votou contra a modificação.

Sugere-se, por conseguinte, que a atual legislação seja modificada para descriminalizar o aborto realizado até o terceiro mês da gestação, visto que até esse período o ser em desenvolvimento depende plenamente da genitora, devendo caber a esta decidir sobre o prosseguimento ou não do processo gestacional, pois o peso dos direitos desta, pelo menos durante o referido lapso temporal, prepondera sobre os direitos daquele. Tal discussão deve ocorrer de forma democrática no âmbito do Poder Legislativo nacional, com a consideração das pesquisas nacionais e internacionais realizadas sobre o tema, com a oitiva de diversos setores da sociedade civil, incluindo, de forma massiva, as mulheres, pois são as principais interessadas, visto que são diretamente impactadas pela proibição normativa. Desse modo, a norma produzida atenderá às necessidades das brasileiras e estará adequada às normas constitucionais vigentes.

\section{Conclusão}

Os temas que foram analisados ao longo do artigo, envolvendo a narrativa do livro 0 conto da aia, os direitos sexuais e reprodutivos das mulheres e o aborto no Brasil demonstram que a sociedade brasileira não está distante da realidade opressora representada na obra literária, pois, assim como nesta, as mulheres sofrem cotidianamente com violações aos seus direitos mais básicos, visto que a proibição legal do aborto pode ser apontada como uma restrição à liberdade das mulheres sobre seus próprios corpos e uma violação dos seus direitos sexuais e reprodutivos.

Apresentou-se, inicialmente, um resumo da narrativa do livro O Conto da Aia, escrito por Margaret Atwood, cuja história relata a existência de uma sociedade na qual as mulheres perdem todos os seus direitos e liberdades, sendo que aquelas que ainda são férteis são destinadas, notadamente, à reprodução. A exposição desta obra objetiva alertar os indivíduos sobre uma realidade concretizável quando as minorias sociais, no caso específico, as mulheres, não participam dos processos decisórios na sociedade e se tornam alvo das restrições impostas. O Brasil é um país onde há uma ínfima participação feminina na política, o que torna a materialização da narrativa ficcional ainda mais plausivel.

Em seguida, destacou-se a existência dos direitos sexuais e reprodutivos como direitos humanos, consagrados por documentos internacionais dos quais o Brasil é signatário, e que preveem a liberdade para lidar com a sexualidade e decidir sobre a reprodução - ressaltandose que o aborto pode ser entendido como um direito reprodutivo, juntamente com o acesso a métodos contraceptivos, políticas de assessoramento e planejamento familiar, que conferem à mulher o direito de livremente escolher o momento em que decidirá reproduzir, sem imposições ou discriminações.

No entanto, no Brasil, desde a sua origem como Estado, o aborto foi considerado crime, o que, como constatado por pesquisas nacionais (DINIZ; MEDEIROS; MADEIRO, 2016) e internacionais (OMS), não impede que esta conduta seja praticada, sujeitando as mulheres à necessidade de buscarem alternativas clandestinas que as colocam em perigo, uma vez que os procedimentos são realizados sem a devida higienização do local e dos instrumentos e sem a presença de profissionais especializados, colocando em risco a saúde e a vida dessas mulheres.

Ao final, analisou-se a decisão proferida pelo Supremo Tribunal Federal, o qual entendeu que os abortos realizados até o terceiro mês da gestação não podem ser configurados como crime, por uma interpretação do Código Penal à luz da Constituição de 1988, tendo em vista que, ao realizar um sopesamento dos direitos conflitantes, verificou-se que o conteúdo intrauterino no referido período teria menos peso do que os direitos fundamentais das mulheres. Por isso, a criminalização dos procedimentos abortivos até o terceiro mês de gravidez seria desproporcional, visto que, além de não conseguir alcançar o objetivo pretendido, qual seja, proteger a vida do produto gestacional, uma vez que não impede que os abortos efetivamente aconteçam, 
também não é a medida menos gravosa, pois viola diversos direitos fundamentais das mulheres que se sobrepõem aos direitos do feto nesse período do seu desenvolvimento.

Propõe-se, ao final, que a sociedade brasileira encare o aborto como uma questão de saúde pública, cuja proibição coloca em risco a vida de milhares de mulheres, sugerindo-se que estas, antes de serem vistas como mães em potencial, devem ser consideradas como seres humanos, dignas de ter e exercer a liberdade para decidir sobre seus próprios corpos e destinos. Cabe ao Estado agir para concretizar essa perspectiva na medida em que prevê a dignidade humana como fundamento da República, bem como a igualdade, a liberdade e os direitos sexuais e reprodutivos como direitos fundamentais. Portanto, o aborto deve ser discutido com profundidade, a partir das pesquisas já realizadas sobre o tema para modificar a atual legislação, que vigora desde 1940 e que não atende às necessidades das brasileiras, pelo contrário, viola seus direitos fundamentais.

\section{Referências}

ALDANA, Myriam; WINCKLER, Silvana. "Direitos reprodutivos: debates e disputas sobre o direito ao aborto no contexto da redemocratização do Brasil". Revista Sequência, Chapecó, v. 30, n. 58, p. 167-183, jul. 2009. Disponível em https://periodicos.ufsc.br/index.php/sequencia/article/view/21777055.2009v30n58p167. Acesso em 05/1 1/2017.

ALVES, Ivanildo Ferreira. Crimes contra a vida. Belém: Unama, 1999.

ALEXY, Robert. Teoria dos direitos fundamentais. Tradução de Virgilio Afonso da Silva. 2. ed. São Paulo: Malheiros, 2015.

ATWOOD, Margaret. "Margaret Atwood: the road to ustopia". The guardian, 14/10/201 1. Disponível em https://www.theguardian.com/books/201 1/oct/14/margaret-atwood-road-to-ustopia. Acesso em 08/1 1/2017.

ATWOOD, Margaret. O conto da aia. Tradução de Ana Deiró. Rio de Janeiro: Rocco, 2017.

BALBINOT, Rachelle Amália Agostini. "O aborto: perspectivas e abordagens diferenciadas". Revista Sequência, n. 46, p. 93-1 19, jul. 2003. Disponível em https://periodicos. ufsc.br/index.php/sequencia/ article/view/15293. Acesso em 12/11/2017.

BBC. "7 COISAS que as mulheres sauditas não podem fazer mesmo após alcançarem direito a dirigir". BBC, 28/09/2017. Disponível em http://www.bbc.com/portuguese/internacional-41431798. Acesso em 10/11/2017.

BíBLIA. A. T. "Gênesis". In: Bíblia. Português. Bíblia Sagrada. Tradução de Ivo Storniolo e Euclides Martins Balancin. São Paulo: Paulus, 2005.

BRASIL, Ministério da Justiça e Cidadania - Secretaria Especial de Políticas para as Mulheres. Balanço 2015: uma década de conquistas - ligue 180. 2015. Disponível em https://assetscompromissoeatitude-ipg.sfo2.digitaloceanspaces.com/2016/03/balanco-ligue-180_2015.pdf. Acesso em 13/12/2017.

BRASIL. Lei no 10.406, de 10 de janeiro de 2002. Institui o Código Civil. Disponível em goo.gl/tB90g Acesso em 10/11/2017.

BRASIL. Lei $n^{\circ} 3.071$, de $1^{\circ}$ de janeiro de 1916. Código Civil dos estados unidos do Brasil. Disponível em goo.gl/c006gb. Acesso em 10/1 1/2017.

BRASIL. Decreto-lei no 2.848, de 7 de dezembro de 1940. Código Penal. Disponível em goo.gl/t0Tjp. Acesso em 15/1 1/2017.

BRASIL, Supremo Tribunal Federal. Ação de descumprimento de preceito fundamental $n^{\circ}$ 54/DF. Tribunal pleno. Ministro relator: Marco Aurélio. Braślila. Julgado em 12 de abril de 2012. Disponível em goo.gl/LYfpQH. Acesso em 11/1 1/2017.

BRASIL, Supremo Tribunal Federal. Habeas corpus no 124.306/RJ. Ministro relator: Marco Aurélio. Brasília. Julgado em 29 de novembro de 2016. 2016. Disponível em goo.gl/GWtHhR. Acesso em $17 / 11 / 2017$

BRASIL, Ministério da Saúde. Secretaria de Políticas de Saúde. Área Técnica de Saúde da Mulher. Parto, aborto e puerpério: assistência humanizada à mulher. Brasília: Ministério da Saúde, 2001. 
CAPEZ, Fernando. Curso de direito penal. Parte especial: dos crimes contra a pessoa a dos crimes contra o sentimento religioso e contra o respeito aos mortos (arts. 121 a 212). 15. ed. São Paulo: Saraiva, 2015. v.2.

CORRÊA, Sônia; PETCHESKI, Rosalind. "Direitos sexuais e reprodutivos: uma perspectiva feminista". Physis: Revista de Saúde Coletiva [online], v. 6, n. 1-2, p. 147-177, 1996. ISSN 0103-7331. Disponível em https://doi.org/10.1590/S0103-7331 1996000100008. Acesso em 11/11/2017.

DINIZ, Debora; MEDEIROS, Marcelo; MADEIRO, Alberto. "Pesquisa nacional de aborto 2016". Ciência \& Saúde Coletiva [online], v. 22, n. 2, p. 653-660, 2017. Disponível em https://www.scielo.br/scielo. php?pid=S1413-81232017000200653\&script=sci_abstract\&tIng=pt. Acesso em 15/1 1/201 7 .

FORMENTI, Lígia. "Diariamente, 4 mulheres morrem nos hospitais por complicações do aborto". 0 Estado de São Paulo, 2016. Disponível em goo.gl/zy2NR6. Acesso em 15/1 1/2017.

HAJE, Lara. "Comissão aprova licença maior para a mãe de bebê prematuro e define que a vida começa na concepção". Câmara dos Deputados, 08/1 1/2017. Disponível em goo.gl/cekMnF. Acesso em 17/11/2017.

HUNGRIA, Nelson; FRAGOSO, Cláudio Heleno. Comentários ao código penal. 6. ed. Rio de Janeiro: Forense, 1981, v.5.

IBGE. Instituto Brasileiro de Geografia e Estatística. Síntese de indicadores sociais: uma análise das condições de vida da população brasileira: 2016. Rio de Janeiro: IBGE, 2016. Disponível em https://biblioteca.ibge.gov.br/visualizacao/livros/liv98965.pdf. Acesso em 11/1 1/2017.

MANCUSO, Cecília. "Speculative or science fiction? As Margaret Atwood shows, there isn't much distinction". The guardian [online], 10/08/2016. Disponível em goo.gl/C8UhJN. Acesso em 09/1 1/2017.

MASHAL, Mujib. "Contra tradição masculina, mulheres afegãs fazem campanha pelo uso do nome próprio em público". Uol notícias [online], 6/08/2017. Disponível em goo.gl/SztSab. Acesso em 30/12/2017.

OMS. Organização Mundial da Saúde. "Proibição não reduz número de abortos e aumenta procedimentos inseguros". Organização das Nações Unidas, 2017. Disponível em goo.gl/8XGcpo. Acesso em 17/1 1/2017.

ONU. Organização das Nações Unidas. "Declaração e plataforma de ação da IV Conferência Mundial sobre a Mulher. Pequim". Organização das Nações Unidas, 1995. Disponível em goo.gl/ WUXL3g. Acesso em 10/1 1/2017.

ONU. Organização das Nações Unidas. "Relatório da conferência internacional sobre população e desenvolvimento. Plataforma de Cairo". Organização das Nações Unidas, 1994. Disponível em goo.gl/WpzcCJ. Acesso em 10/1 1/2017.

VINEYARD, Jennifer. "Margaret Atwood comenta bases reais do livro e série 'O Conto da Aia'". Folha de S. Paulo [online], 19/06/2017. Disponível em https://www1.folha.uol.com.br/ ilustrada/201 7/06/1893807-margaret-atwood-comenda-bases-reais-do-livro-e-serie-o-conto-daaia.shtml. Acesso em 11/11/2017.

Ana Carolina Pessoa Holanda (a.carolinapholanda@hotmail.com) é bacharel em Direito pela Universidade de Fortaleza. Especialista em Direito e Processo Constitucional pela Universidade de Fortaleza. Mestra em Direito Constitucional pela Universidade de Fortaleza.

Rafael Marcílio Xerez (rafaelmx@unifor.br) é professor dos Cursos de Pós-Graduação (Mestrado/Doutorado) em Direito da Universidade de Fortaleza - UNIFOR. Mestre em Direito pela Universidade Federal do Ceará - UFC. Doutor pela Universidade Federal da Bahia - UFBA. Juiz titular da $2^{a}$ Vara do Trabalho de Fortaleza. 


\section{COMO CITAR ESSE ARTIGO DE ACORDO COM AS NORMAS DA REVISTA}

HOLANDA, Ana Carolina Pessoa; XEREZ, Rafael Marcílio. "O Conto da Aia e o aborto no Brasil: a ausência de liberdade da mulher sobre o próprio corpo". Revista Estudos Feministas, Florianópolis, v. 29, n. 1, e61052, 2021

\section{CONTRIBUIÇĀO DE AUTORIA}

Ana Carolina Pessoa Holanda - leitura e análise da obra literária O Conto da Aia, utilizada como base para a elaboração do artigo, pesquisa das normas, produções acadêmicas e jurisprudência atinentes ao tema do aborto, bem como com a produção do texto final.

Rafael Marcílio Xerez - fornecimento de fontes de pesquisa e bases teóricas, elaboração, revisão e correção do texto final do artigo.

\section{FINANCIAMENTO}

Fundação Cearense de Apoio ao Desenvolvimento Científico e Tecnológico (FUNCAP) com bolsa de pesquisa para Mestrado Acadêmico.

\section{CONSENTIMENTO DE USO DE IMAGEM}

Não se aplica.

\section{APROVAÇĀO DE COMITÊ DE ÉTICA EM PESQUISA}

Não se aplica.

\section{CONFLITO DE INTERESSES}

Não se aplica.

\section{LICENÇA DE USO}

Este artigo está licenciado sob a Licença Creative Commons CC-BY 4.0 International. Com essa licença você pode compartilhar, adaptar, criar para qualquer fim, desde que atribua a autoria da obra.

\section{HISTÓRICO}

Recebido em 15/01/2019

Reapresentado em 28/04/2020

Aprovado em 12/06/2020 